\title{
LOGÍSTICA URBANA E PLANEJAMENTO TERRITORIAL: UMA ABORDAGEM POLÍTICA
}

\section{URBAN LOGISTICS AND TERRITORY PLANNING: A POLITICAL APPROACH}

\author{
Fander de Oliveira Silva ${ }^{1}$ \\ William Rodrigues Ferreira ${ }^{2}$ \\ Universidade Federal de Uberlândia, Brasil
}

\begin{abstract}
RESUMO
A globalização aprofundou suas estratégias capazes de fomentar a competição global e de definir os agentes hegemônicos dessa corrida, que de um lado estão grandes corporações em concorrência e de outro os trabalhadores em uma luta de classes, sendo os atributos expressos a esse globaritarismo os responsáveis pelo (re) ordenamento do território, impactando na política, economia e cultura da sociedade. Portanto, a problemática apresentada tem servido como referência para a importância de analisar o conceito de logística sob o olhar geográfico e empresarial, compreendendo a sua atuação e limitações a partir de procedimentos metodológicos que abrange desde levantamento bibliográfico sobre a temática até o mapeamento das condições atuais do sistema de transportes de cargas na cidade.
\end{abstract}

Palavras Chave: Logística; Geografia dos Transportes; City Logistics.

\begin{abstract}
Globalization has deepened its strategies to foster global competition and to set its hegemonic agents having, on one side, large corporations in competition and, on the other side, workers on a

\footnotetext{
1 Mestrando em Geografia pelo Instituto de Geografia da Universidade Federal de Uberlândia, Brasil.

E-mail: fanderoliveira@hotmail.com

2 Professor Doutor Associado da Universidade de Uberlândia, Brasil. E-mail: wferreira@ufu.br
} 
Fander de Oliveira Silva, William Rodrigues Ferreira. Logística urbana e planejamento territorial: uma abordagem política

DOI: http://dx.doi.org/10.15359/rgac.1-56.2

class struggle, where the attributes in this globalization process are the ones responsible for spatial planning of cities, thus impacting politics, economy, and culture of the society. Therefore, the problems stated have served as a significant reference to analyze the concept of logistics from a geographic and business perspective by understanding their role and limitations from methodological procedures that range from literature on the subject to the mapping of current conditions of the cargo transportation system in the city.

Keywords: Logistics; Transportation Geography; City Logistics.

\section{RESUMEN}

La globalización ha profundizado sus estrategias fomentando la competencia global y definiendo los agentes hegemónicos de esta; teniendo por un lado la competencia de grandes corporaciones y por otro lado a los trabajadores en una disputa de clases, en donde los atributos de este proceso globalizador son los responsables del ordenamiento territorial de la ciudades, impactando a su vez en la política, la economía y la cultura de una sociedad. Por lo tanto, la problemática presentada ha servido como un importante referente para el análisis de la logística como concepto desde una perspectiva geográfica y empresarial, al comprender su actuación y limitaciones a partir de procedimientos metodológicos que abarcan desde el levantamiento bibliográfico de la temática, hasta el mapeo de las condiciones actuales del sistema de transportes de carga en la ciudad.

Palabras clave: Logística; geografía del transporte; logística de la ciudad.

\section{Introdução: transporte e território sob o olhar geográfico}

Os processos de urbanização e industrialização das cidades brasileiras, que aqui consideramos processos inerentes, se deram de forma peculiar e sua evolução foi pautada a partir da influência das redes de transporte que se estabeleceram no território.

O movimento de pessoas, bens e informações sempre foram componentes fundamentais da sociedade sendo este período de globalização a que pertencemos (caracterizado pela convergência técnica, científica e informacional) marcado pela força de grandes corporações.

Neste sentido, o transporte têm se revelado como um dos principais componentes centrais dos sistemas de produção local, nacional e global, sendo uma das pautas importantes de interesse mundial principalmente nos países desenvolvidos, onde há uma integração econômica diretamente ligada ao setor. As viagens de um local a outro e a distribuição de bens e serviços (regulares ou eventuais) são processos cada vez mais comuns principalmente a partir da motorização das massas urbanas, da urbanização e industrialização brasileira em meados de do século XX.

O Transporte, no entanto, não significa necessariamente qualquer tipo de movimento, uma vez que 
El transporte supone movimiento, sin embargo, ello no implica que cualquier tipo de movimiento se identifique necessariamente com la función $<<$ transporte $>>$. Antes bien, cuando se habla de $<<$ movimento $>>$, como lá función essencial del transporte, se están implicando necessariamente diversos elementos de tipo material: los contenidos, o aquello que és susceptible de ser transportado; el material móvil, o aquello mediante lo cual se transportan los contenidos; y, finalmente, la infraestructura o material fijo, sobre el que se realiza el transporte o que sirve al transporte mismo. (Pons; ReynéS, 2004, p.33).

Para Segado, Garcia e Rosique (1996), desde uma perspectiva funcional de movimento de pessoas, bens ou informações as redes de transportes cumprem suas funções de acessibilidade territorial, atrelamento ao sistema produtivo e também a sua própria dinâmica de produção, tendo um papel importante na interpretação das relações físicas e socioeconômicas do território.

Objeto de estudo de diversas ciências, o transporte não é um assunto privado de determinadas áreas do conhecimento. Pela sua própria essência, é uma temática de estudo multidisciplinar, pelo qual os sociólogos, políticos, historiadores, arquitetos, economistas, engenheiros, geógrafos entre outros tem um importante papel na contribuição dos seus desdobramentos teórico-conceituais e técnicos.

Primeiramente, sistemas de transportes, movimentos, infra-estrutura e instalações (rede de transportes) estão ocupados em uma área substancial no espaço geográfico, associados à idéia de distância e poder pelo qual concebe o caráter dinâmico e móvel do território-rede, que na concepção reticular mais restrita de território, Haesbaert (2004) pondera:

"Pensando a rede não apenas enquanto mais uma forma (abstrata) de composição do espaço, no sentido de um 'conjunto de pontos e linhas', numa perspectiva euclidiana, mas como o componente territorial indispensável que enfatiza a dimensão temporal-móvel do território e que, conjugada com a 'superfície' territorial, ressalta seu dinamismo, seu movimento, suas perspectivas de conexão ('ação distância', como destaca Machado, 1998) e 'profundidade' relativizando a condição estática e dicotômica (em relação ao tempo que muitos concedem ao território enquanto território-zona num sentido mais tradicional" (Haesbaert, 2004, p. 286-87). 
Fander de Oliveira Silva, William Rodrigues Ferreira. Logística urbana e planejamento territorial: uma abordagem política

DOI: http://dx.doi.org/10.15359/rgac.1-56.2

Admitindo-se o caráter multifuncional e dinâmico, a rede de transportes é um conjunto interligado de rotas específicas ou não onde circulam pessoas, informações, capitais e mercadorias e ainda são capazes de protagonizar as ações de ordenamento e (re) ordenamento do território. Para Raffestin (1993) a produção do território se dá por estas interações espaciais e conseqüentemente aos desejos dos Poder Público sobre os interesses coletivos, que através das redes (cada vez mais influenciadas pelas atuações de grandes empresas no mercado), torna-se o território o lócus privilegiado para suas práticas de gestão territorial e campo de poder, dinâmica e disputas de interesses.

Dada os interesses e ações do Poder Público sob influências das grandes empresas, são as redes de transportes que vão dominar a (re)configuração do território, promover níveis de complexidade e eficácia territorial, podendo ser redes equilibradas, conexas e desenvolvimentistas nas diferentes escalas, como também redes desarmônicas, desequilibradas que polarizam o território, e que concomitantemente incrementa as desigualdades sócio-políticas, culturais e econômicas.

Sabendo-se que o território é uma das cinco categorias de análise da Geografia e que está intimamente vinculado a rede de transportes, estes vão ser os pilares básicos que constitui a Geografia dos Transportes, que tem como preocupação peculiar a relação dos fenômenos espaciais e a sua explicação.

Baseado em duas idéias principais, Taaffe (1996) refere-se a Geografia dos Transportes como uma ciência "integradora", na qual aponta duas possíveis essências: o transporte por si só é o maior complexo industrial em termos de uso do solo, emprego e funções e a outra em que os serviços e instalações de transportes no seu todo ou em partes, são os maiores fatores que afetam a distribuição espacial, o desenvolvimento de economias e atividades sociais.

Cabe à Geografia incorporar as discussões que se referem à mobilidade inclusiva e sustentável da circulação de pessoas, bens e informações, e suas respectivas interações que se dão no território, em razão dos intensos processos que ocorrem atualmente na produção e no consumo, onde as conseqüências são perceptíveis na dinâmica dos centros urbanos saudáveis e sustentáveis. Onde a logística urbana é fator fundamental, mas que, vem sendo relegada nos processos, discussões e intervenções de planejamento e ordenamento territorial das cidades brasileiras. 
Em sua maioria, os centros urbanos do Brasil, não estão e nem são bem amparados para intervir e propor soluções nos conflitos entre o transporte de pessoas e cargas. A poluição sonora e ambiental, a dificuldade diária de circulação, faltas de área de carga e descarga, infra-estrutura precária, falha de comunicação, entre outros são os problemas mais comuns encontrados.

Dessa forma, há explicitamente a necessidade de se abordar a discussão da "logística urbana de cargas" e a sua eficiência no planejamento urbano, em razão da premência da questão tanto para o setor produtivo e para sociedade quanto para os gestores públicos, pois a circulação de bens e serviços é imprescindível na qualidade do desenvolvimento social, político, ambiental e econômico da urbis, como já foi apontado.

Portanto, a problemática apresentada tem servido como referência para a reflexão dos seus conceitos, estruturas, funções, arranjos e importância no planejamento físico-político e econômico do território.

\section{Estrutura teórica-conceitual: do transporte e estocagem à su- pply chain managment}

Desde a Segunda Guerra Mundial a Logística tem apresentado uma contínua evolução na morfologia do trânsito urbano e no seu conceito funcional. Em meados do século XX era compreendida como transporte e estocagem de produtos e ao longo do seu desenvolvimento chegou a ser considerada junto ao Marketing um dos principais pontos estratégicos do sistema de produção integrado, incorporando e inovando de acordo com o moderno conceito Supply Chain Managment (SCM).

Nos sistemas produtivos um dos elementos básicos é a distância espacial entre a indústria e os mercados consumidores, de um extremo a distância da fábrica com as matérias-primas e de outro os artifícios necessários para a produção das mercadorias, como por exemplo: mão-de-obra, suplementos, adornos, materiais e ferramentas. Assim a mercadoria ao chegar a seu destino final satisfazendo o desejo do cliente tem um valor agregado, que Novaes (2007) define como valor de lugar.

Considerando importante o deslocamento da mercadoria e sua alocação ao destino, outros dois elementos relevantes são a qualidade e o tempo que devem ser considerados e agregados ao valor final. Como exemplo, consideremos a entrega de marmitas em Uberlândia no horário de almoço em que o tráfego nas vias é intenso e há um contingente número de pessoas 
Fander de Oliveira Silva, William Rodrigues Ferreira. Logística urbana e planejamento territorial: uma abordagem política

DOI: http://dx.doi.org/10.15359/rgac.1-56.2

se movimento casa-trabalho e vice-versa, saindo o motoboy de um restaurante no bairro Umuarama com destino a uma empresa de grande porte no bairro Luizote. Este serviço precisa ser realizado de forma ágil e com planejamento eficaz dentro do prazo estabelecido pelo cliente e ainda com qualidade, isto é, com a temperatura adequada, com marmitas apropriadamente embaladas e em condições saudáveis para ser consumida.

A partir destes pilares, temos ainda um elemento que agrega valor e tem sido muito aproveitado pelas atividades logísticas que é a informação, que vai desde a inserção de códigos de barra, rastreamento até a customização de rótulos individuais para cada tipo de consumidor. Com isso, embora seja agregado o valor da informação ao valor final, o empresa tende à ter "fidelidade" dos clientes diante dos seus concorrentes, já que está tem uma cadeia produtiva que soma valores positivos.

Além de agregar os valores supracitados, os sistemas produtivos também tem procurado dispensar do seu sistema tudo o que acarreta perda de tempo e mais custos para a empresa e que conseqüentemente torna as mercadorias mais caras ao bolso do cliente, perfazendo o que chamamos de Logística.

Figura 1: Valores da Cadeia Produtiva.

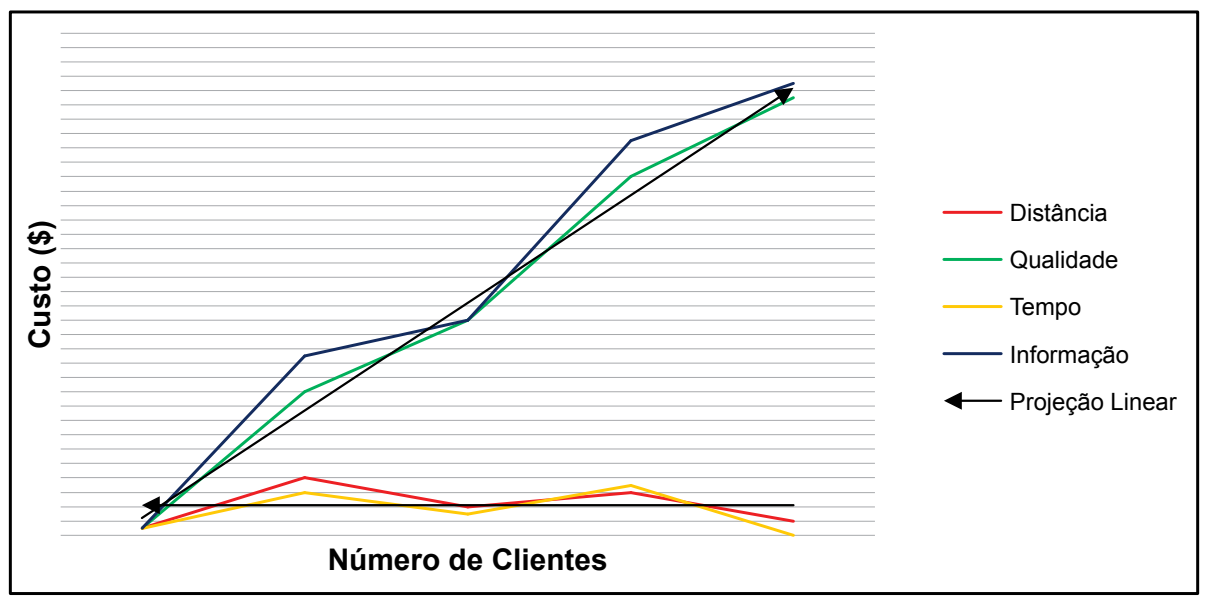

Fonte: NOVAES, 2007. Org. e Adaptação: SILVA, 2015. 
Diante do que foi exposto, o conceito de logística tem sua formulação baseada em profissionais da engenharia, administração e economia.

A Logística trata de todas as atividades de movimentação e armazenagem, que facilitam o fluxo de produtos desde o ponto de aquisição da matéria-prima até o ponto de consumo final, assim como dos fluxos de informação que colocam os produtos em movimento, com o propósito de providenciar níveis de serviço adequados aos clientes a um custo razoável. (Ballou, 1993, p.24.)

"É o processo com o qual se dirige de maneira estratégica transferência e a armazenagem de materiais, componentes e produtos acabados, começando dos fornecedores, passando através das empresas, até chegar aos consumidores." (Kobayashi, 2000, p.18).

Atendendo as evoluções tecno-científicas e culturais dos sistemas de produção, a Logística teve o seu processo de desenvolvimento divido por Novaes (2007) em quatro fases: Atuação Segmentada, Integração Rígida, Integração Flexível e Integração Estratégica.

$\mathrm{Na}$ primeira fase, as empresas tinham pouco interesse no estoque e suas ações eram voltadas nas economias que poderiam ter usando modais de transporte de menor custo e com maior capacidade, e se interessavam em transportadoras que realizassem o serviço com menor frete possível. Cada empresa tinha sua visão corporativa de reduzir custo e encontrar o menor frete possível, ainda que o serviço prestado fosse precário, que a título de ressalva, o ainda hoje temos empresas que atuam nesta perspectivas.

Em uma segunda fase, com a inserção de produtos especiais, customizados e diferenciados (tamanho, material, cor, design, textura, etc.) as poucas opções que eram oferecidas agora estavam sobre um leque ampliado de diversos tipos de mercadorias e concomitante novos hábitos alimentares e produtos supérfluos foram incorporados a necessidade da sociedade. Tida o êxodo rural, o aumento da frota de veículos, a crise do petróleo no início da década de 1970, e conseqüentemente as restrições de movimentação de veículos de carga no tráfego intra-urbano os movimentos logísticos que envolviam a produção, custos de transferência e distribuição cresceram subitamente e como resultado tivemos maiores custos de transporte, mão-de-obra, matéria-prima, entre outros colaborando para 
Fander de Oliveira Silva, William Rodrigues Ferreira. Logística urbana e planejamento territorial: uma abordagem política

DOI: http://dx.doi.org/10.15359/rgac.1-56.2

a elevação dos custos logísticos. Foi neste momento que surgiu o desenvolvimento de novas alternativas de transporte, a multimodalidade. Usos combinados de trens, navios, caminhões e até aviões começaram a ser intensificados visando a redução de custos e o aproveitamento dos modais.

A terceira fase da Logística é marcada pela introdução eletrônica de dados, pela integração nos níveis intra-empresariais e inter-relações dos fornecedores com clientes. Com o desenvolvimento da telecomunicação e informática houve a possibilidade de uma integração flexível no acompanhamento de estoques e vendas com a inserção do código de barras, processos estes que antes eram levantados manualmente e requisitavam muito tempo. Nesta fase têm-se uma preocupação com os desejos do cliente e a busca permanente por uma produção just-in-time e do "estoque zero".

Ainda segundo Novaes (2007) temos uma quase fase, conhecida pelo conceito de Supply Chain Managment (SCM). Nesta fase ocorre um salto qualitativo onde as empresas passam a tratar a questão logística como estratégia para garantir competitividades e induzir novos negócios. Diferente das outras três etapas antecessoras em que a integração se dava basicamente em termos físicos e operacionais, agora a Logística troca informações confidenciais, promove parcerias e faz investimentos, tratando-a como o elemento diferencial do mercado globalizado onde as disputas e a concorrência cada vez mais são acirradas.

Também são características desta fase modelos como o postponement que seria uma espécie de produção da mercadoria/acessórios no movimento do transporte do próprio produto para o seu cliente e o agile emterprises que são fábricas de mercadorias de alto valor agregado localizada junto a aeroportos, atuando com agilidade os pedidos feitos pelo e-commerce. Recentemente tem se acrescentado a esta fase a crescente preocupação com a mobilidade sustentável, surgindo a Logística Reversa (processo de recuperação de materiais diversos através da reciclagem) que hoje é palco de discussões mundiais.

No entanto, cabe ressaltar os trabalhos de Lummus, Krumwiede e Vokurka (2001) e de Ross (1998), aos quais situam a Logística como uma "componente" aliado a (SCM) e afirmam que ela está geralmente associada a corporações empresariais, ainda que realizem conexões entre fornecedores-empresa e empresa-consumidor e que a (SCM) é a compreensão de um corpo amplo, que assume todos os fluxos desde o fornecedor até o consumidor. 
Já o trabalho de Metz (1998) adota a progressão lógica do desenvolvimento da logística: "Integrated Supply Chain Management (ISCM) is a process-oriented, integrated approach to procuring, producing, and delivering products and services to customers. ISCM has a broad scope that includes sub-suppliers, suppliers, internal operations, trade customers, retail customers, and end users". (Metz, 1998).

Corroborado por Novaes (2007) que pressupõe as suas quatro fases já explanadas, Christopher (1992) diz que a (SCM) trata-se de uma rede de organizações, através de ligações nos dois sentidos, dos diferentes processos e atividades que produzem valor na forma de produtos e serviços que são colocados nas mãos do consumidor final, conforme a figura 2 retrata no esquema a seguir:

Figura 2: Valores e Fases da Logística Urbana segundo Novaes, 2007.

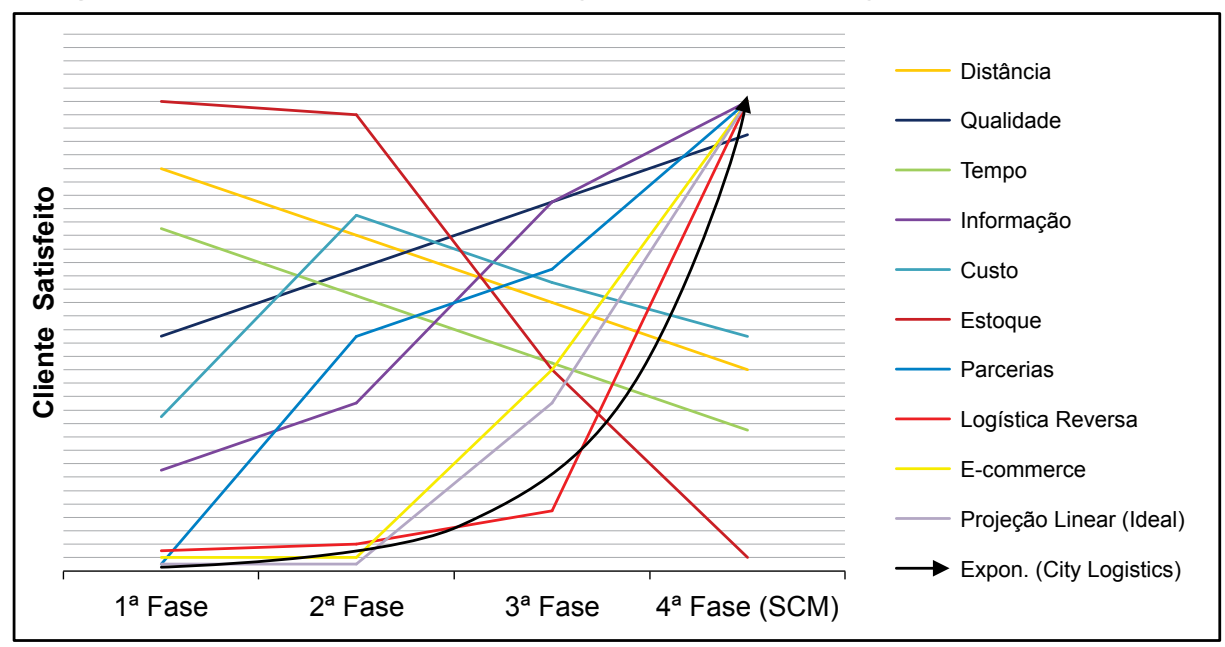

Fonte: NOVAES, 2007. Org. e Adaptação: SILVA, 2015.

Desta forma, entendemos que para atuar aos modernos conceitos e práticas da $(S C M)$ é necessário se remeter a evolução da cadeia produtiva até que se atinja o estágio de Gestão da Cadeia de Suprimentos. Consideremos a (SCM) como uma integração entre os estágios logísticos em que os seus agentes atuam simultaneamente de forma estratégica desde o fornecedor até o consumidor, gerando produtos e serviços no menor tempo, 
Fander de Oliveira Silva, William Rodrigues Ferreira. Logística urbana e planejamento territorial: uma abordagem política

DOI: http://dx.doi.org/10.15359/rgac.1-56.2

distância e custo possível e melhor qualidade para o cliente, que é a essência de tais interações espaciais.

Estas interações espaciais, as quais Corrêa (1997) qualifica como "amplo e diverso deslocamento multidirecional com diferentes intensidades de fluxos e velocidades", ao interagir com o cenário urbano de cargas passou a sofrer com o caos urbano de congestionamento, imobilidade, inacessibilidade, estrutura viária inadequada, equipamentos urbanos sucateados, falha de comunicação, entre outros.

Dessa forma surge o conceito de City Logistics de forma pioneira na Dinamarca em meados da década de 1990 (França et al, 2005) como uma "raiz" da Logística Urbana que vai aprofundar suas ações muito além do transporte de cargas, que vai orientar todos os aspectos produtivo-econômicos, sócio-políticos e ambientais do transporte de cargas da cidade em uma visão holística de mobilidade urbana sustentável considerando os custos e benefícios tanto do setor público quanto do privado.

"O Conceito de City Logistics remete ao conjunto de iniciativas práticas implantadas com o objetivo de minimizar as problemáticas da Logística Urbana (no que se refere aos sistemas de transportes, operações de cargas e descargas, emissões de poluentes, etc.), considerando o caráter sistêmico da cidade. Assim a City Logistics enquanto um modelo de cidade consiste na orientação para as ações de Logística Urbana.” (Vilela, et al., 2013).

Desde as medidas de traffic calming, sistemas de cooperação de transporte de cargas, centros logísticos até vias subterrâneas para escoamento de mercadorias, as propostas da Logística Urbana têm caminhado cada vez mais no sentido de incorporar o conceito de City Logistics. Neste sentido, Taniguchi et al. (2003) fundamenta três pilares, conforme figura 3 , pelos quais todas as soluções precisam estar pautadas: 
Figura 3: Pilares da City Logistics segundo Taniguchi et. al., 2003.

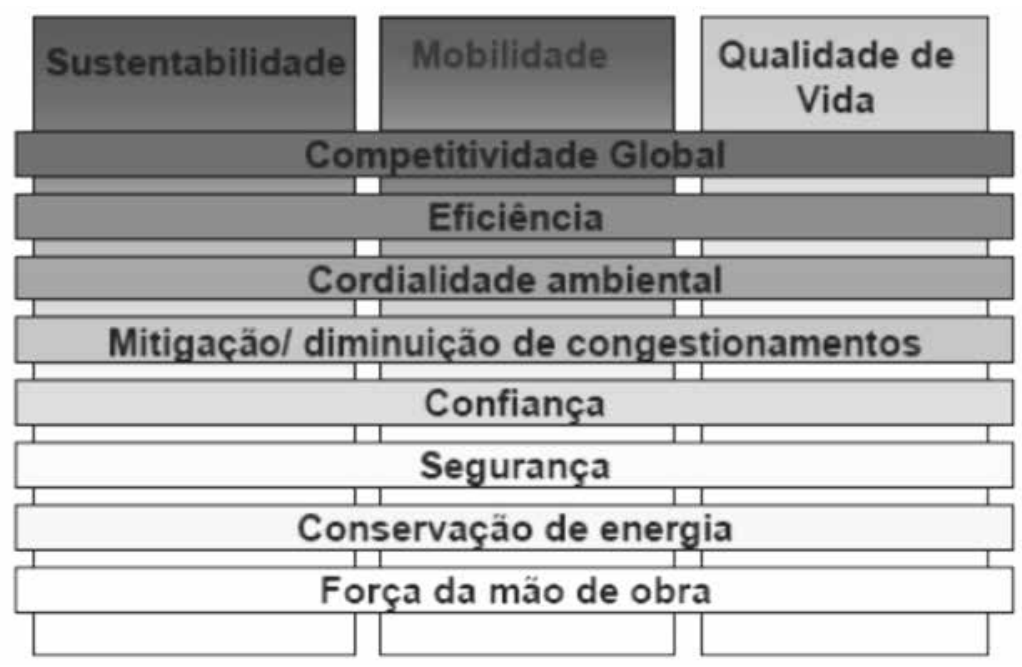

Fonte: Taniguchi et. al., 2003. Org. e Adaptação: Silva, 2015.

Assim a Logística Urbana apresenta-se como um complexo industrial que oferece bens e serviços aos seus clientes dentro de parâmetros ambientais, sócio-espaciais e econômicos. Sendo o meio de investimentos, tal pela sua capacidade de interação e influência do território com as atividades de produção na distribuição espacial das atividades socioeconômicas.

Dado o seu valor em níveis econômicos, sua importância vai desde ao nível macro concedido pela sua relação com estratégias nacionais de integração entre os diferentes locais de produção ao comércio internacional, mediado pelas macro-diretrizes ao qual o Plano CNT 2014 exemplifica:

"O presente Plano, em nível nacional, abrange o transporte de passageiros e cargas, cujas infraestruturas compreendem o conjunto de vias dedicadas aos diversos modais - rodovias, ferrovias, hidrovias e aerovias - e os terminais de passageiros - estruturas destinadas ao embarque, desembarque e transferência de passageiros - e de cargas - estruturas destinadas ao processamento e/ou à transferência de carga entre veículos distintos, de iguais ou diferentes modalidades de transporte." (CNT, 2014.)

Como também ao nível micro pelos seus desdobramentos ligados ao custo de produção e impacto nos preços das mercadorias, como também nas estratégias municipais, mediadas na maioria das cidades pelo Plano 
Fander de Oliveira Silva, William Rodrigues Ferreira. Logística urbana e planejamento territorial: uma abordagem política

DOI: http://dx.doi.org/10.15359/rgac.1-56.2

Diretor ou Plano de Mobilidade, como é o caso de Uberlândia em que "racionalizar a circulação de bens e mercadorias" é uma das diretrizes gerais do Plano Diretor de Transporte e Mobilidade Urbana de Uberlândia (2010), ao qual atende o Plano Diretor de Uberlândia, aprovado através da Lei Complementar n432/06, em 19 de outubro de 2006.

Neste mesmo sentido, a legislação tem se tornado cada vez mais determinante na definição do modelo de distribuição urbana e no (re)ordenamento do território. Embora sua importância em níveis macro e micro-econômico esteja estampada, a carga urbana ainda não é tratada como um problema prioritário devido às políticas nacionais relegarem aos municípios um "problema local", sendo a maioria dos municípios carentes de equipes habilitadas e com condições de compreender e propor soluções a complexidade da carga urbana.

\section{Políticas e planejamento territoria}

O cenário atual é extremamente dependente dos transportes e, quando discutimos sobre logística urbana de cargas, apresentamos no Brasil uma tardia preocupação no que se refere à regulamentação e disposição do uso e ocupação do solo, do tratamento da questão urbana no território brasileiro.

A pouco menos de trinta anos foi sancionada a Constituição de 1988, pela qual são destinados dois artigos (Art.182 e 183) a tratar da política urbana. Regulamentadora desses dois artigos, treze anos depois surge a Lei $\mathrm{n}^{\circ} 10.257$, trazendo a caótica realidade urbana brasileira novos rumos e possibilidades territoriais.

Proposto com princípios originais, objetivos determinados, diretrizes inovadoras e instrumentos singulares o Estatuto da Cidade vem a tratar do uso e parcelamento do solo, edificação, desapropriação, direito de superfície e preempção, outorga onerosa do direito de construir, estudo de impacto de vizinhança, questão democrática no planejamento das cidades, plano diretor, entre outros. Sendo este último, o instrumento que consideramos neste texto o mais importante no que tange a Logística Urbana.

O plano diretor constituído pelo Art. $4^{\circ}$ do Estatuto da Cidade como um dos instrumentos de planejamento municipal (assim como o zoneamento ambiental, os planos de desenvolvimento econômico e social, parcelamento do uso e ocupação do solo), tem se tornado o principal instrumento da política urbana brasileira. 
Arroladas as diretrizes urbanísticas gerais, a política urbana tem por objetivo ordenar o pleno desenvolvimento das funções sociais da cidade e propriedade urbana mediante a garantia do transporte como um dos seus elementos. Objetiva o cumprimento da função social do território urbano, atendida quando satisfeita as exigências fundamentais da cidade que assegura o atendimento dos cidadãos no seu conceito de qualidade de vida, justiça social e desenvolvimento econômico.

Atrelado ao inciso XX do Art. 21 e o Art.182 da Constituição Federal e ao previsto no Art. 2 e Art. 40 do Estatuto da Cidade, se institui recentemente a Política Nacional de Mobilidade Urbana (Lei $\mathrm{N}^{\circ}$ 12.587, de 3 de Janeiro de 2012), que objetiva contribuir para o acesso universal à cidade, o fomento e a concretização das condições que contribuam para a efetivação dos princípios, objetivos e diretrizes da política de desenvolvimento urbano, por meio do planejamento e da gestão democrática.

Este instrumento, voltado à questão da mobilidade municipal, vem organizar e coordenar os modais de transporte, de serviços e infraestuturas que garante o deslocamento de pessoas e cargas no território do município, considerando para seus fins o transporte urbano de cargas o serviço de transporte de bens, animais e mercadorias. No entanto, compreendo na íntegra a política, é possível identificar que o transporte urbano de cargas tem sua preocupação relegada, o que deixa a desejar o planejamento e gestão do transporte de cargas no território.

O resultado deste cenário é a complexidade e a alta competividade nos serviços de distribuição que provocam graves problemas de acessibilidade ao espaço da cidade e as suas atividades urbanas (trabalho, lazer, compras, etc.), a poluição sonora, acidentes, stress, dentre outros. Logo nota-se a importância de um estudo em função de viabilizar a logística urbana de cargas, apresentando maneiras de desenvolver os sistemas de transporte e circulação para satisfazer as necessidades de mobilidade, do desenvolvimento econômico e bem estar social.

Diante do pressuposto, entende-se que os centros urbanos brasileiros, onde se concentra aproximadamente $85 \%$ da população brasileira (IBGE, 2010) com uma taxa de motorização de 1:4,4 habitantes (Denatran, 2010), tem seu processo histórico e de formação um ligeiro crescimento populacional e adensamento urbano, pelo qual não foi acompanhado pela 
Fander de Oliveira Silva, William Rodrigues Ferreira. Logística urbana e planejamento territorial: uma abordagem política

DOI: http://dx.doi.org/10.15359/rgac.1-56.2

melhoria e qualidade de vida no que se diz respeito a mobilidade tanto de pessoas quanto de cargas.

É possível se identificar a poluição ambiental e sonora, a dificuldade diária do trânsito onde a frota pesada de veículos de cargas circulam em horários de pico sem qualquer restrição nas grandes vias das cidades brasileiras, transtornos para estacionar, falta de áreas de carga e descarga de mercadorias, infraestrutura viária precária, falha de comunicação entre empresa e governantes, dentre outros.

Portanto, embora seja tardia, temos atualmente importantes elementos de regulamentação para se pensar e realizar a função social da cidade, uma vez que atribuída a estas normativas básicas do ordenamento territorial urbano a implementação de políticas públicas norteadoras dos rumos a serem tomados por cada cidade no que se refere à logística urbana de cargas, de acordo com as suas necessidades e interesses específicos.

A logística está criada, o que muda é o olhar e a forma de analisá-la no território. Há de se reforçar o papel do Estado no entendimento da logística como técnica de desenvolvimento econômico-social, mas também de segregação, de pobreza, desequilíbrios e desigualdades, ligadas a movimentos de mercadorias e estratégias capitalistas que configuram o atual território a que estamos incumbidos.

\section{Considerações finais}

De um modo geral notemos que o conceito de logística se formou a partir do estágio de urbanização, portanto cada cidade está a um determinado nível, o que exige do Poder Público local investimento em um específico diagnóstico e soluções que tratem o conceito. A carência de informações das atividades ligadas à carga urbana, trabalhos fragmentados e específicos e os inexpressivos números de pesquisas desenvolvidas a finco que tratem a carga urbana são um dos impasses que dificultam a ação do Poder Público, que pouco tem se avançado nas investigações sobre o intra-urbano.

Atualmente a situação da logística urbana nas cidades brasileiras está longe do conceito de Supply Chain Managment ou mesmo das exigências de uma City Logistics. Nossos centros urbanos têm sua atenção voltada à resolução de problemas que atrapalhem o funcionamento do transporte público e privado de pessoas. Ainda assim, o transporte de pessoas é visto como principal agente nas interações espaciais e que por conseqüência o ciclista, 
o pedestre e a carga urbana são deixadas em segundo plano, embora sejam componentes importantes responsáveis pela vitalidade da cidade.

A ineficiência e desmazelo com a situação da logística urbana fez com que o setor privado cada vez mais buscasse oportunidades de melhoria na distribuição, alternativas just-in-time e estratégias territoriais que visassem o lucro das corporações locais. Longe disso, o Poder Público que deveria mediar e acompanhar tais interações, tem o seu papel finalizado quando tenta controlar os impactos causados pelas decisões corporativas com medidas temporárias ou curativas.

No Brasil, a nível federal as políticas públicas como a Política Nacional de Mobilidade Urbana, a Política Nacional de Trânsito, O Estatuto da Cidade, entre outras priorizam o transporte público e não enfrentam o transporte de cargas como uma prerrogativa no planejamento e isso acaba se reproduzindo nas políticas municipais. No entanto, temos cidades como São Paulo, Porto Alegre, Curitiba, Cascavel que asseguram em seus planos a mobilidade de cargas e apontam à um planejamento que minimiza os custos de tempo e espaço, usa recursos renováveis, racionalização e promovem eficácia nos fluxos e caminham na garantida da igualdade de acesso e recursos, na proteção e saúde ambiental e no desenvolvimento econômico.

Sobre as funções dos centros urbanos brasileiros, as distâncias entre casa e trabalho, entre fornecedor-cliente, origem-destino, geram fluxos de pessoas, bens e serviços, trazendo os problemas já comentados. Tal situação, bem como o papel do Poder Público e do Setor Privado no transporte de cargas urbanas precisa ser colocado em pauta nas políticas tanto federais quanto municipais e na prática, no lócus urbano, objetivando-se o bem estar comum que garanta o direito igual do acesso à cidade.

\section{Referências}

Ballou, R.H. (1993). Logística empresarial: transportes, administração de materiais e distribuição física. São Paulo : Atlas.

Brasil. (2014). Ministério dos Transportes; Confederação Nacional do Transporte. Plano CNT de Transporte e Logística. Brasília.

Christopher, M. (1992). Logistics and Supply Chain Management. London: Pitman Publishing.

Christopher, M. (2007). Logística e gerenciamento da cadeia de suprimentos. São Paulo: Thomson. 
Fander de Oliveira Silva, William Rodrigues Ferreira. Logística urbana e planejamento territorial: uma abordagem política

DOI: http://dx.doi.org/10.15359/rgac.1-56.2

Corrêa, R. (1997). “Interações Espaciais”. In: CASTRO, Iná Elias de; GOMES, Paulo César da Costa; CORREA, Roberto Lobato. Explorações Geográficas. Rio de Janeiro: Betrand Brasil, p. 279-318.

França, P.T. y Rubin, M. (s.d) "Transporte Urbano de Mercadorias, Logística Urbana e City Logistics”. Grupo de estudos logísticos - GELOG/UFSC. Florianópolis.

Haesbaert, R. (2004) O mito da desterritorialização: do "fim dos territórios" à multi territorialidade. Rio de Janeiro: Bertrand Brasil.

Kobayashi, S. (2000). Renovação da logística: Como definir estratégias de distribuição física global. São Paulo: Atlas, 2000.

Lummus, R. Krumwiede, D. W. Vokura, R. J. (2001). "The relationship of logistic to supply chain management: developing a common industry definition". Industrial Management \& Data Systems, Emerald, 101, 426-431.

Metz, P. J. (1998). "Demystifying Supply Chain Management". Supply Chain Management Review, 1, 46-55.

Novaes, A. (2007). Logística e gerenciamento da cadeia de distribuição: estratégia, operação e avaliação. 3. ed. Rio de Janeiro: Elsevier.

Pons, J.M. y Reynés, M. (2004). Geografía de los transportes. Universitat de les Illes Balears.

Raffestin, C. (1993). Por uma geografia do poder. São Paulo: Ática.

Ross, F. D. (1998). Competing through Supply Chain Management-creating market-winning strategies through supplu chain partnerships. USA: Chapman \& Hall.

Segado, F. Garcia, A., y Rosique, F.(1996). Topografia aplicada para ingerieros. Universidad de Murcia, 329p.

Taaffe, E.J., Gauthier, H.L., O'kelly y Morton, E. (1996). Geography of transportation. New Jersey: Prentice-Hall.

Taniguchi, E. y Thompson, R.G. (2003). Logistic Systems for Sustainable Cities: Proceedings of the 3 Internaicional Conference on City Logistics (Madeira, Portugal, 25-27 June, 2003) Japão: Emerald.

Uberlândia, Prefeitura Municipal. (2006). "Lei Complementar no432 de 19 de outubro de 2006”. Dispõe sobre o Plano Diretor Municipal de Uberlândia/MG, 2006. Disponível em <http://www.uberlandia. mg.gov.br/uploads/cms_b_arquivos/2273.pdf $>$ 